
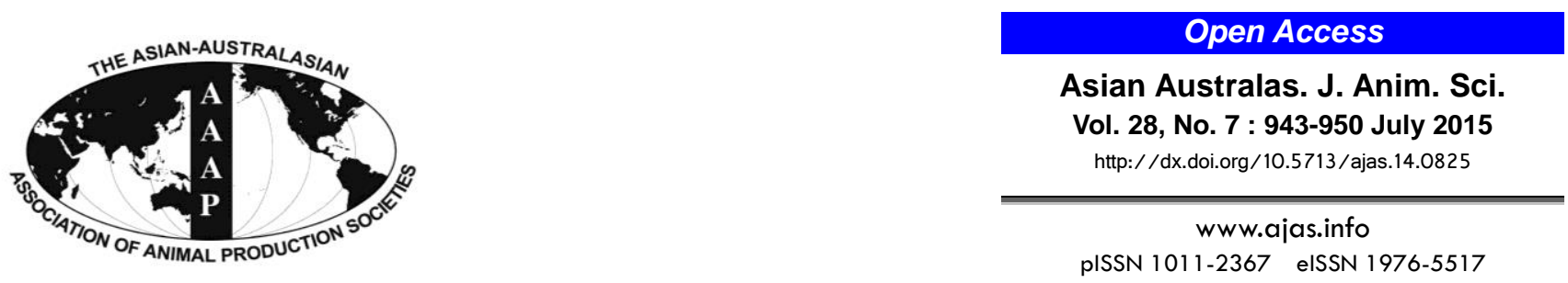

\title{
Influence of Temperature and Humidity on Pregnancy Rate of Murrah Buffaloes under Subtropical Climate
}

\author{
Soumya Dash*, A. K. Chakravarty, V. Sah', V. Jamuna, R. Behera, N. Kashyap, and B. Deshmukh \\ Dairy Cattle Breeding Division, National Dairy Research Institute, Karnal-132 001, Haryana, India
}

\begin{abstract}
Heat stress has adverse effects on fertility of dairy animals. Decline in fertility is linearly associated with an increase in combination of both temperature and humidity. The purpose of this study was to investigate the relationship between temperature humidity index (THI) and the pregnancy rate of Murrah buffaloes in a subtropical climate. The effects of genetic and non-genetic factors viz., sire, parity, period of calving and age group at first calving were found non-significant on pregnancy rate. The effect of THI was found significant $(\mathrm{p}<0.001)$ on pregnancy rate of Murrah buffaloes calved for first time and overall pregnancy rate. The threshold THI affecting the pregnancy rate was identified as THI 75 . The months from October to March showed THI $<75$ and considered as non heat stress zone (NHSZ), while months from April to September were determined as heat stress zone (HSZ) with $\mathrm{THI} \geq 75$. The lowest overall pregnancy rate $(0.25)$ was obtained in July with THI 80.9 , while the highest overall pregnancy rate $(0.59)$ was found in November with THI 66.1. May and June were identified as critical heat stress zone (CHSZ) within the HSZ with maximum decline (-7\%) in pregnancy rate with per unit increase in THI. The highest overall pregnancy rate was estimated as 0.45 in NHSZ with THI value 56.7 to 73.2 . The pregnancy rate was found to have declined to 0.28 in HSZ with THI 73.5 to 83.7. However, the lowest pregnancy rate was estimated as 0.27 in CHSZ with THI value 80.3 to 81.6. (Key Words: Pregnancy Rate, Threshold Temperature Humidity Index, Non Heat Stress Zone, Heat Stress Zone, Critical Heat Stress Zone, Murrah Buffaloes)
\end{abstract}

\section{INTRODUCTION}

Buffaloes are generally reared in the subtropical region where they are exposed to wide range of temperature and humidity. The district Karnal belongs to Haryana, a home tract of Murrah buffaloes in India where the climatic parameters like temperature in summer reach up to $47^{\circ} \mathrm{C}$ and decline to the extent of $1^{\circ} \mathrm{C}$ during winter. In tropical and subtropical climate, high ambient temperature is the major constraint on animal productivity (Marai et al., 2008). Although buffaloes are polyestrous, they exhibit a seasonal variation in display of oestrus, conception rate and calving (Sing and Nanda, 1993). Few buffaloes exhibit postpartum oestrus during April and May due to maximum air temperature (Abayawansa et al., 2011). The poor

\footnotetext{
* Corresponding Author: Soumya Dash. Tel: +91-94-66-96-62-20, E-mail: dr.soumya10@gmail.com

1 Division of Animal Genetics, Indian Veterinary Research Institute, Izatnagar, Bareilly-243 122, Uttar Pradesh, India. Submitted Oct. 22, 2014; Revised Dec. 30, 2014; Accepted Jan. 26, 2015
}

reproductive performance in buffaloes especially during summer months is due to inefficiency in maintaining the thermoregulation under high environmental temperature and relative humidity (RH) and buffaloes suffer from heat stress. Hot weather is detrimental for buffaloes because of their dark skin and sparse coat of body hair which absorb more heat along with poor heat dissipation mechanism due to less number of sweat glands (Marai and Haeeb, 2010). Heat stress is the combined effect of environmental parameters producing conditions that are higher than the temperature range of the animal's thermal neutral zone (Buffington et al., 1981). The thermo neutral zone of lactating dairy cows ranges between $5^{\circ} \mathrm{C}$ to $25^{\circ} \mathrm{C}$ (Roenfeldt, 1998). Heat stress has deleterious effect on fertility traits of dairy cattle (Ravagnolo and Misztal, 2002). A number of temperature humidity index (THI) models are used to measure the degree of heat stress affecting fertility traits of cattle by using temperature and RH. Yousef (1985) considered the dry bulb temperature and dew point temperature for the formulation of THI. McGowan et al. 
(1996) reported increase in mean seasonal THI above 72 resulted in a significant decrease in first service pregnancy rate in dairy cattle. The negative effects of heat stress on conception rate of Holstein Friesian dairy cows were observed with increase in maximum THI above 75 (GarciaIspierto et al., 2007). The conception rate of Holstein Friesian dairy cows during the hot period was significantly lower $(29.5 \%)$ than cool period (38.2\%) (Nabenishi et al., 2011). The association between THI and pregnancy rate of Bos taurus crossbred cows is negative with a change ($2.06 \%$ ) in pregnancy rate for each unit change in THI during the first breeding season 0 to 21 days (Amundson et al., 2006). According to Oseni et al. (2005), the highest pregnancy rate of dairy cattle occurred in SeptemberNovember $(32 \%)$ and the lowest pregnancy rate in MarchMay (24\%).

However, direct effect of THI on pregnancy rate of Murrah buffaloes in subtropical climatic condition of India is not available in the literature. The critical heat stress zone (CHSZ) in a year has not been identified in relation with maximum depression in pregnancy rate with per unit change in THI value. Due to paucity of information on impact of climate, the present study was designed to find the threshold THI value and CHSZ affecting pregnancy rate in Murrah buffaloes.

\section{MATERIALS AND METHODS}

\section{Location}

The present study was conducted on Murrah buffaloes maintained at Livestock Research Centre, National Dairy Research Institute (NDRI), Karnal, Haryana, India, located at $29^{\circ} 42^{\prime} \mathrm{N}$ latitude and $72^{\circ} 02^{\prime} \mathrm{E}$ longitudes at an altitude of $250 \mathrm{~m}$ above the mean sea level in the bed of IndoGangetic alluvial plain. The climate of Karnal is subtropical in nature. The average annual rain fall is approximately 760 to $960 \mathrm{~mm}$ and maximum rain fall occurs during July and August. The month wise average dry bulb temperature varied from $12.43^{\circ} \mathrm{C}$ in the month of January to $32.54^{\circ} \mathrm{C}$ in May while RH ranged between $42.01 \%$ in April to $80.72 \%$ in August during twenty years period (1993 through 2012).

\section{General management}

Buffaloes were maintained in a loose housing system with brick on edges flooring under group management practice. There was canopy type tree plantation within the paddock and provision of shed area in the manger to protect animals from direct sunlight and inclement weather. This system of housing allowed free movement of buffaloes. The nutritional requirements of buffaloes were made through a standardized balanced ration of seasonal green fodders along with concentrates. The concentrates with $15 \%$ digestible crude protein and $8.3 \mathrm{MJ} / \mathrm{kg}$ dry matter of metabolizable energy was fed at $1.5 \mathrm{~kg} / \mathrm{d} / \mathrm{buffalo}$ for maintenance. The dry animals were provided additional concentrate at $1.5 \mathrm{~kg} /$ buffalo since 21 days before the expected date of calving. Milking animals were given additional concentrate $1 \mathrm{~kg}$ per $2 \mathrm{~kg}$ milk production. The livestock farm of NDRI is a part of associated herd progeny testing programme from 1993 under the network project on buffalo improvement, Indian Council of Agricultural Research, New Delhi. A set of bulls were used for inseminating the female buffaloes and their progenies were used for the evaluation of buffalo bulls for a cycle of 18 months. Under this network project, thirteen sets of Murrah bulls were progeny tested with complete evaluation of seven sets on the basis of their daughter's 305-days or less first lactation milk yield. Oestrus detection was carried out with the help of teaser Murrah bull (vasectomised). Females detected in oestrus were inseminated with frozen semen of progeny tested/test bulls and pregnancy was confirmed after 45 days of insemination through rectal palpation. Vaccination programme was undertaken for prevention against foot and mouth disease, haemorrhagic septicaemia, black quarter and Brucellosis. Only healthy buffaloes were included in the study and abortion, metritis, still birth, retained placenta, delayed calving and other reproductive problems were considered abnormal. Buffaloes were culled twice in a year based on low milk production, poor growth, poor reproductive health and congenital defects.

\section{Fertility data}

The information related to fertility of Murrah buffaloes was obtained from records maintained at Dairy Cattle Breeding Division and Artificial Breeding Research Centre of NDRI, Karnal. A total of 1,379 records of 581 Murrah buffaloes under $1 \mathrm{st}, 2 \mathrm{nd}$, 3rd, and 4th parity spanned over a period of 20 years from July 1993 to December 2012 were collected. Abnormal records were not included for the present study. Days open with more than 350 days were discarded. The data were normalized with mean \pm 3 standard deviation for days open.

Pregnancy rate is a new and recent method of measuring fertility in buffaloes as compared to traditional estimation of days open and conception rate. Pregnancy rate measures the time required for a buffalo to become pregnant after calving. It is defined as the percentage of non-pregnant buffaloes to become pregnant during each 21 days after leaving voluntary waiting period (VWP). Pregnancy rate was computed from days open using formula suggested by Van Raden et al. (2004), as follows:

$$
\text { Pregnancy rate }=21 /(\text { Days open }-V W P+11)
$$

where, VWP is the initial phase of lactation where buffaloes were not inseminated. The VWP of Murrah 
Buffaloes has been standardized as 63 days at NDRI herd (Patil et al., 2014).

\section{Weather data and estimation of temperature humidity index}

Meteorological data pertaining to daily dry bulb temperature $\left(\mathrm{T}_{\mathrm{db}}\right)$ and $\mathrm{RH}$ with corresponding period of study were obtained from Central Soil and Salinity Research Institute (CSSRI), Karnal. The CSSRI is located about $2.9 \mathrm{~km}$ away from the location of study i.e. NDRI herd. Monthly average dry bulb temperature $\left({ }^{\circ} \mathrm{C}\right)$ and $\mathrm{RH}$ (\%) were computed from daily weather information. These data were used to calculate the monthly average dew-point temperature $\left(\mathrm{T}_{\mathrm{dp}}\right)$ by the method of Jensen et al. (1990) as given below.

$$
\mathrm{T}_{\mathrm{dp}}=\frac{116.9+237.3 \times \ln (\mathrm{e})}{16.78-\ln (\mathrm{e})}
$$

Where, e $\left(\mathrm{K}_{\mathrm{pa}}\right)=$ ambient vapour pressure and it was estimated as follows:

$$
e\left(K_{p a}\right)=\frac{(r h \times 0.611 \times e)^{\frac{17.27 \times T_{d b}}{T_{d b}+237.3}}}{100}
$$

Month wise THI values were estimated from January to December by using monthly average dry bulb and dewpoint temperature over twenty years (Yousef, 1985).

$$
\mathrm{THI}=\mathrm{T}_{\mathrm{db}}+\left(0.36 \times \mathrm{T}_{\mathrm{dp}}\right)+41.2
$$

\section{Statistical analysis}

Pregnancy rate of buffaloes varies due to different sires used in breeding programme and non genetic factors like parity, period of calving and age group at first calving. Pregnancy rate of Murrah buffaloes was studied in four parities separately and for overall parity. The overall parity considered all the four parities in the present study. A total of thirteen periods of calving were taken with an interval of 18 months for each period according to progeny testing programme under network project on buffalo improvement. Ages of buffaloes at first calving were classified into three groups using mean and one standard deviation after normalizing the distribution of age at first calving in the population i.e. age group 1: $<37$ months; age group 2: 37 to 53 months and age group 3: >53 months, respectively. A mixed model was fitted using Least-square maximum likelihood programme as proposed by Harvey (1990) to study the effect of genetic and non-genetic factors on pregnancy rate of Murrah buffaloes.
The model was defined as

$$
\mathrm{Y}_{\mathrm{ijklm}}=\mu+\mathrm{S}_{\mathrm{i}}+\mathrm{Pa}_{\mathrm{j}}+\mathrm{P}_{\mathrm{k}}+(\mathrm{AG})_{1}+\mathrm{e}_{\mathrm{ijklm}}
$$

where, $\mathrm{Y}_{\mathrm{ijklm}}$ is the observed pregnancy rate of $\mathrm{m}^{\text {th }}$ buffalo in $1^{\text {th }}$ age group at first calving ( 1 to 3 ) calved in $\mathrm{k}^{\text {th }}$ period of calving ( 1 to 13 ) belonging to $\mathrm{j}^{\text {th }}$ parity ( 1 to 4 ), sired by $i^{\text {th }}$ sire; $\mu$, population mean; $S_{i}$, effect of $i^{\text {th }}$ sire; $\mathrm{Pa}_{\mathrm{j}}$, effect of $\mathrm{j}^{\text {th }}$ parity (1 to 4$)$; $\mathrm{P}_{\mathrm{k}}$, effect of $\mathrm{k}^{\text {th }}$ period of calving (1 to 13 ); $\mathrm{AG}_{1}$, effect of $\mathrm{l}^{\text {th }}$ age group at first calving (1 to 3 ) and $\mathrm{e}_{\mathrm{ijkl}}$ is random error $\sim \mathrm{NID}\left(0, \sigma_{\mathrm{e}}^{2}\right)$.

\section{Identification of threshold temperature humidity index for pregnancy rate}

To assess the effect of THI on pregnancy rate of Murrah buffaloes, a fixed least squares model was applied (Harvey, 1990). The THI values were classified into 8 groups such as 45.00 to $49.99,50.00$ to $54.99,55.00$ to $59.99,60.00$ to $64.99,65.00$ to $69.99,70.00$ to $74.99,80.00$ to 84.99 , and 85.00 to 89.99 , respectively.

The model considered was

$$
\mathrm{Y}_{\mathrm{ij}}=\mu+\mathrm{THI}_{\mathrm{i}}+\mathrm{e}_{\mathrm{ij}}
$$

where, $Y_{i j}$ is the observed pregnancy rate of $j^{\text {th }}$ buffalo under $\mathrm{i}^{\text {th }}$ THI subclasses; $\mu$, overall mean; $\mathrm{THI}_{\mathrm{i}}$, effect of $\mathrm{i}^{\text {th }}$ THI (1 to 8$)$ and $\mathrm{e}_{\mathrm{ij}}$ is random error $\sim \mathrm{NID}\left(0, \sigma^{2}{ }_{\mathrm{e}}\right)$. Pregnancy rate was adjusted with the significant effect of THI. Least-squares means along with standard errors for pregnancy rate under different THI subclasses were estimated. The threshold THI for pregnancy rate was identified above which decline in pregnancy rate occurs with respect to increase in THI value.

The monthly average overall pregnancy rate was plotted against monthly average THI values from January to December over twenty years period to observe the changes in the pregnancy rate in different months in relation to THI values. Accordingly two zones were identified as NHSZ and heat stress zone (HSZ) in a year.

\section{Identification of critical heat stress zone}

The regression analysis was performed by using REG procedure (SAS Institute Inc., version 9.2, Cary, NC, USA) to assess change in pregnancy rate with per unit increase in monthly average THI value both in the first parity and overall parity of Murrah buffaloes.

The model applied was

$$
\mathrm{Y}_{\mathrm{i}}=\mathrm{a}+\mathrm{bx}+\mathrm{e}_{\mathrm{i}}
$$

Where, a is intercept and $e_{i}$ is random residual $\sim$ NID $(0$, $\sigma_{\mathrm{e}}^{2}$ ). The Zone where maximum decline in pregnancy rate 


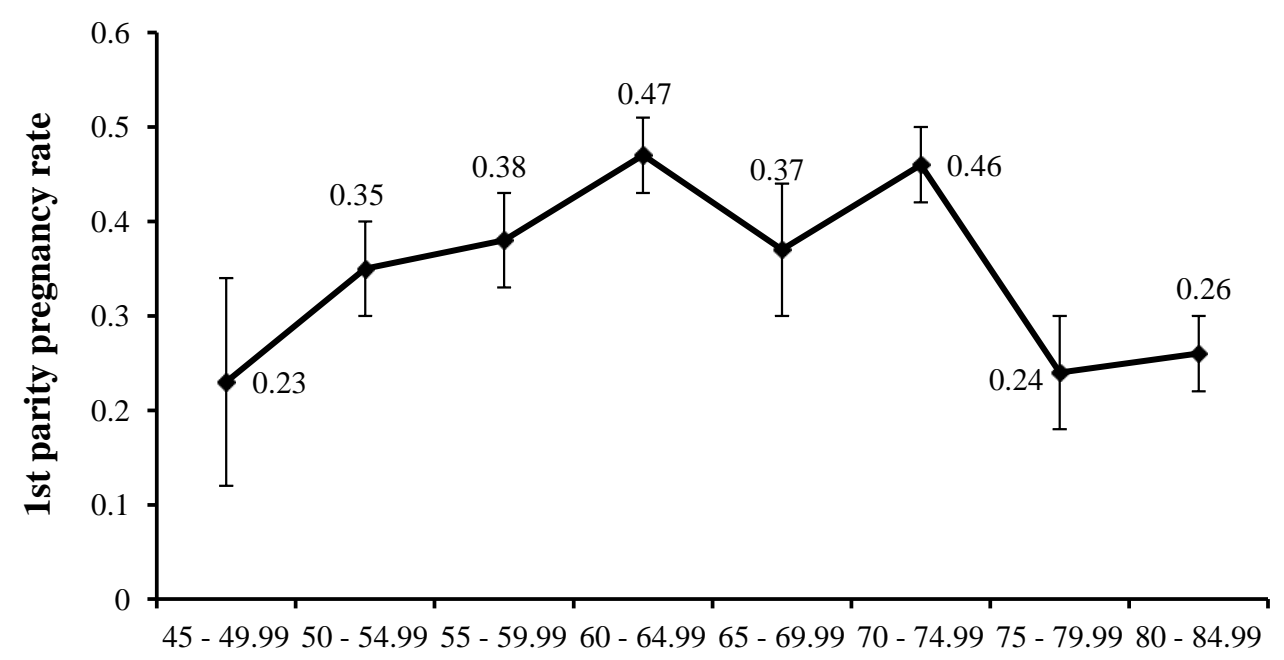

THI subclasses

Figure 1. Least squares means of 1st parity pregnancy rate across temperature humidity index (THI) subclasses.

was observed with per unit rise in monthly average THI value was identified as the CHSZ within the HSZ.

The average pregnancy rate of Murrah buffaloes in the 1st parity and overall parity were evaluated under NHSZ, HSZ, and CHSZ. The comparison of average pregnancy rate in the 1st parity and overall parity in three zones were performed by the proportionate Z-test by using XLSTAT at 0.05 and 0.01 levels of significant probability values.

\section{RESULTS}

\section{Threshold temperature humidity index for pregnancy} rate

The least squares means for pregnancy rate in the $1 \mathrm{st}$ parity and overall parity were obtained as $0.34 \pm 0.02$ and $0.38 \pm 0.02$, respectively. The genetic and non-genetic factors like sire, parity, period of calving and age group at first calving had no significant effects on the pregnancy rate of
Murrah buffaloes. The effect of THI was highly significant $(p<0.001)$ on pregnancy rate of Murrah buffaloes calved for first time and overall pregnancy rate. Figure 1 and 2 shows the relationship of 1 st parity pregnancy rate and overall pregnancy rate with eight different THI sub classes viz; 45 to $49.9,50$ to $54.9,55$ to $59.9,60$ to $64.9,65$ to $69.9,70$ to $74.9,75$ to $79.9,80$ to 84.9 , respectively. A distinct relationship between increase in THI and decline in pregnancy rate was observed in the present study. The $1^{\text {st }}$ parity pregnancy rate was estimated as 0.46 for THI subclass 70 to 74.9 which was decreased to 0.24 at $\mathrm{THI} \geq 75$ (Figure 1). The overall pregnancy rate was obtained as 0.41 for THI subclass 70 to 74.9 which was declined to 0.25 with onset of THI $\geq 75$ (Figure 2). This study indicates both 1 st parity pregnancy rate and overall pregnancy rate started to decline above THI 75. Therefore, THI value 75 was identified as the threshold THI for pregnancy rate of Murrah buffaloes.

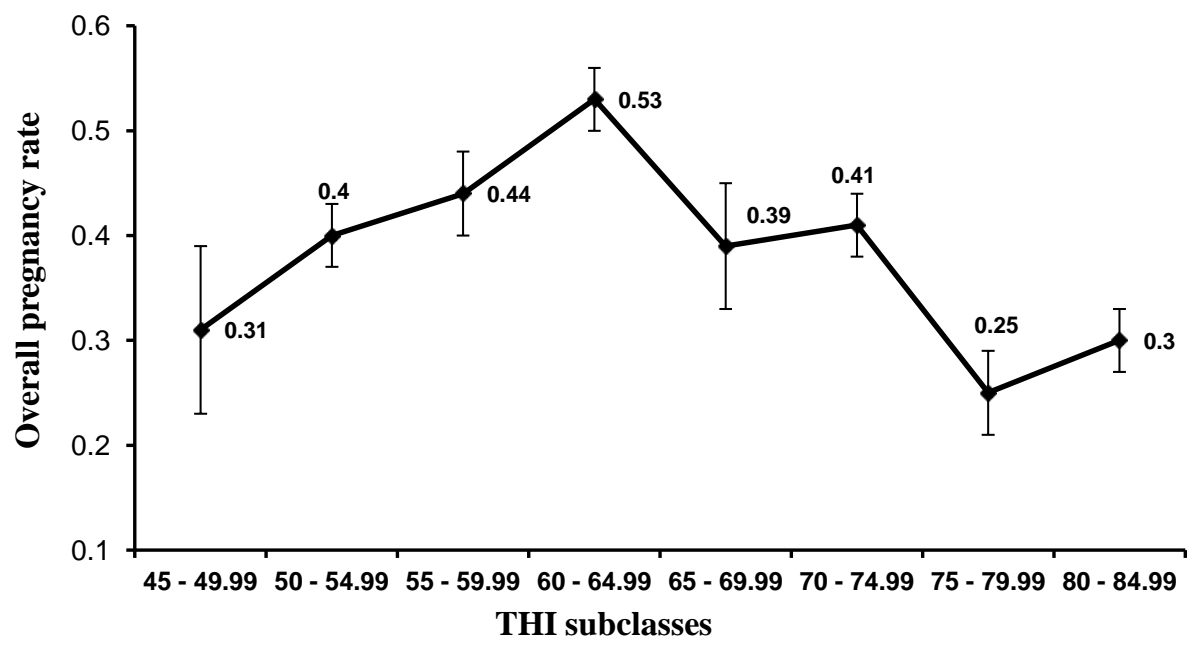

Figure 2. Least squares means of overall pregnancy rate across temperature humidity index (THI) subclasses. 


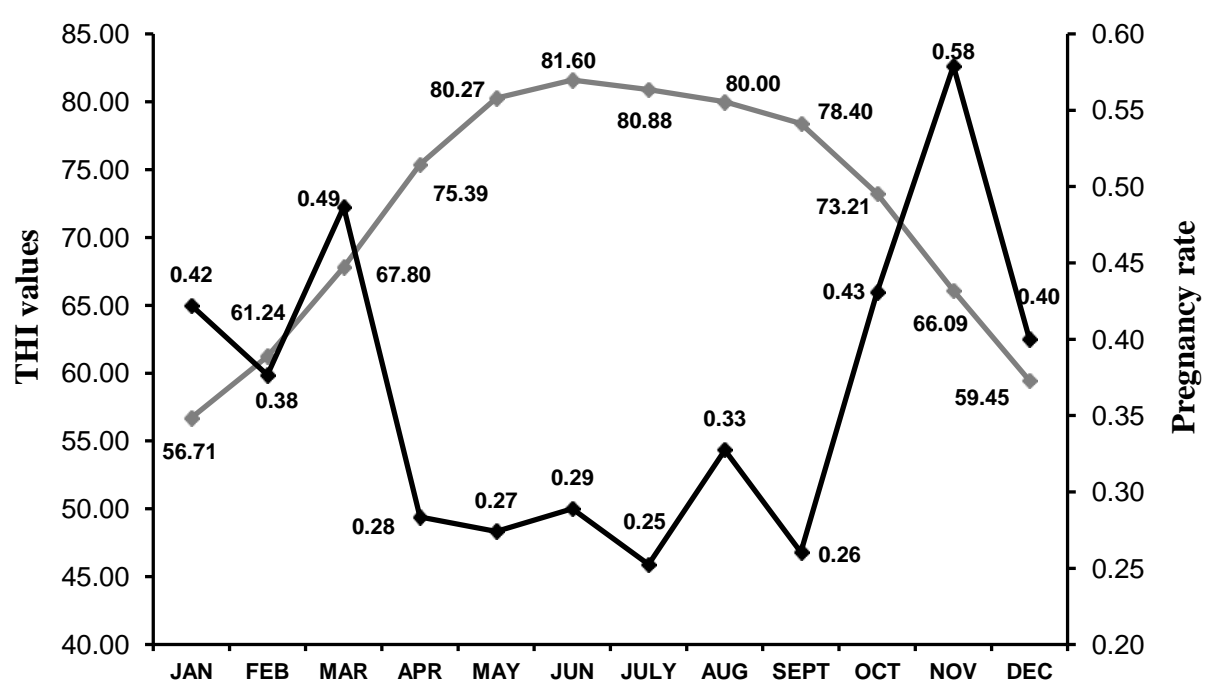

Figure 3. Month wise average pregnancy rate and temperature humidity index (THI) values during 1993 through 2012.

Monthly average THI $<75$ was found from months October to March, while THI $\geq 75$ was obtained during the months from April to September (Figure 3). On observing the variability of THI values with the corresponding pregnancy rate of Murrah buffaloes, two zones were identified i.e. NHSZ with THI $<75$ and HSZ with THI $\geq 75$. The results revealed that pregnancy rate was affected at THI $\geq 75$, but THI $<75$ was favourable for high pregnancy rate of Murrah buffaloes.

The variation in monthly average pregnancy rate corresponding with monthly average THI values from January to December over twenty years is depicted in Figure 3. The lowest pregnancy rate $(0.25)$ was obtained with respect to average THI 80.88 in the month of July and it varied between 0.25 to 0.33 during April to September. The highest pregnancy rate $(0.58)$ was found with THI 66.09 in the month November and it ranged between 0.38 to 0.58 during October to March.

\section{Identification of critical heat stress zone}

A negative association was found between THI and pregnancy rate. The 1 st parity pregnancy rate was decreased by $6 \%$ for each unit change in monthly average THI value under HSZ (Table 1). However, there was maximum decline $(-11 \%)$ in 1 st parity pregnancy rate with per unit increase in THI value for the months May and June.

The negative association was also found between THI
Table 1. Decline in 1st parity pregnancy rate and overall pregnancy rate in relation to THI in Murrah buffaloes

\begin{tabular}{lccccccc}
\hline \multirow{2}{*}{ Zone } & \multicolumn{3}{c}{ 1st parity } & & \multicolumn{3}{c}{ Overall parity } \\
\cline { 2 - 4 } \cline { 6 - 7 } & $\mathrm{a}$ & $\mathrm{b}$ & $R^{2}(\%)$ & $\mathrm{a}$ & $\mathrm{b}$ & $R^{2}(\%)$ \\
\hline $\begin{array}{l}\text { NHSZ } \\
\quad \text { Oct to Mar) }\end{array}$ & -5.57 & 0.09 & 29.61 & & 1.20 & -0.01 & 0.75 \\
$\begin{array}{l}\text { HSZ } \\
\quad \text { (Apr to Sept) }\end{array}$ & 5.21 & -0.06 & 5.06 & & 3.47 & -0.04 & 2.68 \\
$\begin{array}{c}\text { CHSZ } \\
\quad \text { (May to Jun) }\end{array}$ & 8.90 & -0.11 & 14.75 & 5.74 & -0.07 & 7.55 \\
\hline
\end{tabular}

THI, temperature humidity index; $a$, intercept; $b$, regression coefficient; $R^{2}$, coefficient of determination; NHSZ, non heat stress zone; HSZ, heat stress zone; CHSZ, critical heat stress zone.

and overall pregnancy rate under NHSZ and HSZ with $-1 \%$ and $-4 \%$ changes in pregnancy rate for each unit change in monthly average THI value. On the other hand, there was maximum decrease $(-7 \%)$ in overall pregnancy rate with per unit increase in THI for the months of May and June (Table 1). Therefore, May and June were identified as CHSZ for both the 1st parity pregnancy rate and overall pregnancy rate of Murrah buffaloes.

\section{Pregnancy rate estimates in different zones}

The estimates of pregnancy rate of Murrah buffaloes in NHSZ, HSZ, and CHSZ with the corresponding average THI and range of THI values are presented in Table 2. The average pregnancy rate in the 1 st parity of Murrah buffaloes

Table 2. Average 1st parity and overall pregnancy rate of Murrah buffaloes in different zones

\begin{tabular}{|c|c|c|c|c|c|}
\hline Zone & Months & THI (Average) & THI (Range) & 1st parity & Overall parity \\
\hline NHSZ & October - March & 64.1 & $56.7-73.2$ & $0.40(255)$ & $0.45(575)$ \\
\hline HSZ & April - September & 79.4 & $75.4-81.6$ & $0.26(162)$ & $0.28(380)$ \\
\hline CHSZ & May, June & 80.9 & $80.3-81.6$ & $0.22(29)$ & $0.27(91)$ \\
\hline
\end{tabular}

THI, temperature humidity index; NHSZ, non heat stress zone; HSZ, heat stress zone; CHSZ, critical heat stress zone.

Figures in parenthesis are number of observations. 
was estimated as 0.40 in NHSZ with average THI 64.1 (56.7 to 73.2). This was decreased to 0.26 at average THI 79.4 (75.4 to 81.6) in HSZ and further decreased to 0.22 with average THI 80.9 (80.3 to 81.6) in CHSZ. First parity pregnancy rate was found to be significant $(p<0.01)$ between NHSZ and HSZ and significant $(p<0.05)$ between NHSZ and CHSZ. Less number of buffaloes showed estrus in CHSZ as compared to HSZ and NHSZ. The highest overall pregnancy rate was estimated as 0.45 in NHSZ which was decreased to 0.28 in HSZ and the lowest pregnancy rate was 0.27 in CHSZ. Highly significant ( $p<$ 0.001 ) difference for overall pregnancy rate was observed NHSZ and HSZ and between NHSZ and CHSZ. The number of buffaloes was also found declined substantially from 575 in NHSZ to 380 in HSZ. Further out of 380, only 91 buffaloes were found pregnant in CHSZ (Table 2).

\section{DISCUSSION}

The THI is a common indicator of heat stress used in cattle and buffaloes for production performance in tropical and subtropical climatic conditions. The scale was originally established in 1960s after taking into account the combined effect of environmental temperature and $\mathrm{RH}$. Increased productivity of dairy buffaloes leads to rise in metabolic heat production. Buffaloes show a poor thermal tolerance power due to presence of less number of sweat glands and under developed thermo regulatory system (Marai and Haeeb, 2010). Hence they are unable to get rid of excess metabolic heat and susceptible to heat stress.

The average pregnancy rate of Murrah buffaloes was estimated as $0.38 \pm 0.02$. Patil et al. (2014) obtained a similar result of 0.35 daughter pregnancy rate in the 1 st parity in Murrah buffaloes. In the present study, the threshold THI for pregnancy rate was identified as 75 in Murrah buffaloes. McGowan et al. (1996) reported that there was significant $(p<0.05)$ decrease in first service pregnancy rate of dairy cattle and an increase in number of services per pregnancy with an increase in THI above 72 which corresponds to temperature $25^{\circ} \mathrm{C}$ and $\mathrm{RH} 50 \%$ in Queensland. When THI on the day of service is more than 72 , it results in decline in conception rate of dairy cows in Australia (Morton et al., 2007). Garcia-Ispierto et al. (2007) identified the negative association of conception rate of Holstein dairy cows with increase in THI in north eastern Spain where there was decrease in conception rate from $35 \%-33 \%$ to $21 \%-27 \%$ at THI values higher than 75 . The water buffalo is the polyestrous animal and the sexual activities occur all round year but it shows a distinct seasonal variation in the display of estrus and conception rate (Singh and Nanda, 1993). When there is maximum air temperature during April and May, very less number of buffaloes exhibit postpartum oestrus and there is a negative correlation $(\mathrm{r}=-0.6)$ between monthly postpartum oestrus incidence and mean maximum temperature (Abayawansa et al., 2011). The high RH and maximum air temperature produce higher THI, which is responsible for lowering the incidence of postpartum oestrus and fertility. The cool environment with lower THI favours the higher fertility in buffaloes.

Our findings indicate that buffaloes in the subtropical region are exposed to heat stress due to high THI values from the month of April to September with a range 75.4 to 81.6. The climate in the months from October to March was favourable for Murrah buffaloes with a range of THI 56.7 to 73.2. In our study, months from October to March were considered as NHSZ with THI $<75$ and April to September as HSZ with THI $\geq 75$. Armstrong (1994) categorized THI values into four different classes as comfort zone (THI <71), mild stress (72 to 79 ), moderate stress (80 to 89 ) and severe stress (>90). Nabenishi et al. (2011) in South-western Japan developed two periods in a year i.e. cool period from October to June with am THI under 75 and hot period from July to September with am THI over 75. In north eastern Spain, Garcia-Ispierto et al. (2007) classified two periods in a year such as cool period including months from October to April with the range of THI 42.9 to 57.7 and warm period including months from May to September with the range of THI from 61.0 to 73.0 .

In our study, the lower overall pregnancy rate of Murrah buffaloes was found in a range 0.25 to 0.33 from April to September and higher pregnancy rate was obtained in a range 0.38 to 0.58 from October to March. In United States, Oseni et al. (2005) reported the pregnancy rate of Holstein cows as $29 \%, 24 \%, 29 \%$, and $32 \%$ for month of calving December to February, March to May, June to August and September to November, respectively. Silent heat is one of the deleterious features to the reproductive performance in the buffaloes and it is due to poor oestrus expression and intensity of heat in buffaloes during summer as compared to winter (Madan and Prakash, 2007). Parmar and Mehta (1994) reported that weak symptoms of oestrous exhibited by buffaloes during summer are due to the lower synthesis and secretion of oestradiol-17 beta by the ovarian follicles. Heat stress causes hyperprolactinemia which results in reduction of luteinizing hormone secretion and oestradiol production in anoestrus buffaloes (Palta et al., 1997) leading to ovarian inactivity. The survival of embryo in the uterus is impaired due to the deficiency of progesterone in the hot season (Bahga and Gangwar, 1988). This endocrine pattern may be partially responsible for the low sexual activities and low fertility in summer season in the buffaloes. In summer the non availability of good quality of feed and fodder may result in poor reproductive performance of buffaloes. The poor nutrition and high environmental temperature are the two major factors responsible for long anoestrous in Murrah buffaloes (Kaur and Arora, 1984). 
In our study, May and June were identified as CHSZ for both 1 st parity pregnancy rate and overall pregnancy rate of Murrah buffaloes. Amundson et al. (2006) observed the negative association of THI with pregnancy rate of Bos taurus cross bred cows and there was $-2.06 \%$ changes in pregnancy rate for each unit of change in THI during the first 21 day of the breeding season. The lowest average pregnancy rate of Murrah buffaloes was obtained under CHSZ as compared to the HSZ and NHSZ along with the decrease in number of buffaloes from NHSZ to the CHSZ. Mellado et al. (2010) indicated the variation in the pregnancy rate of Beefmaster cows in different seasons in a year. The lowest pregnancy rate was observed as $0.44 \pm 0.02$ in April-June (spring) while October-December (fall) months showed peak pregnancy rate $0.62 \pm 0.02$ in Beefmaster cows. In cattle under sub-tropical environments, Burrow (2012) suggest that breeding programmes must consider both productive and adaptive traits if they are to be effective and advised to quantify impacts of environmental stressors across breed types for economic weightings to be used in selection for each breed type and environment. The present research finding will help in incorporating such traits for genetic selection of buffaloes in sub tropical climatic conditions.

In conclusion, the results of the study revealed that THI 75 was the threshold level for the onset of heat stress affecting pregnancy rate in Murrah buffaloes. May and June were identified as the CHSZ with a maximum decline of $7 \%$ pregnancy rate with per unit increase in THI value. The study indicates management interventions are needed to ameliorate the decline in pregnancy rate during the CHSZ under the subtropical climate.

\section{ACKNOWLEDGMENTS}

The authors are thankful to the Director, National Dairy Research Institute (NDRI) for providing necessary infrastructure and facilities for the successful completion of research work. Special thanks to Indian Council of Agricultural Research (ICAR), Ministry of Agriculture, Govt. of India for proving Junior Research Fellowship to the first author for conducting the study.

\section{REFERENCES}

Abayawansa, W. D., S. Prabhakar, A. K. Singh, and P. S. Brar. 2011. Effect of climatic changes on reproductive performance of Murrah buffaloes in Punjab: A retrospective analysis. Indian J. Anim. Sci. 81:334-339.

Amundson, J. L., T. L. Mader, R. J. Rasby, and Q. S. Hu. 2006. Environmental effects on pregnancy rate in beef cattle. J. Anim. Sci. 84:3415-3420.

Armstrong, D. V. 1994. Heat stress interaction with shade and cooling. J. Dairy Sci. 77:2044-2050.

Bahga, C. S. and P. C. Gangwar. 1988. Seasonal variations in plasma hormones and reproductive efficiency in early postpartum buffalo. Theriogenology 30:1209-1223.

Bianca, W. 1962. Relative importance of dry- and wet-bulb temperatures in causing heat stress in cattle. Nature 195:251252.

Buffington, D., A. Collazo-Arochu, G. H. Canton, D. Pritt, W. W. Thatcher, and R. J. Collier. 1981. Black globe-humidity index (BGHI) as comfort equation for dairy cows. Trans. Am. Soc. Agric. Eng. 24:711-714.

Burrow, H. M. 2012. Importance of adaptation and genotypex environment interactions in tropical beef breeding systems. Animal 6:729-740.

Garcia-Ispierto, I., F. Lopez-Gatius, G. Bech-Sabat, P. Santolaria, J. L. Yaniz, C. Nogareda, F. De Rensis, and M. Lopez-Bejar. 2007. Climate factors affecting conception rate of high producing dairy cows in northeastern Spain. Theriogenology 67:1379-1385.

Harvey, W. R. 1990. User's Guide for LSMLMW. PC-2 Version, mixed model least squares and maximum likelihood computer programme, Mimeograph. Ohio State University Press, Columbus, OH, USA.

Nabenishi, H., H. Ohta, T. Nishimoto, T. Morita, K. Ashizawa, and Y. Tsuzuki. 2011. Effect of the temperature-humidity Index on body temperature and conception rate of lactating dairy cows in southwestern Japan. J. Reprod. Dev. 57:450-456.

Jensen, M. E., R. D. Burman, and R. G. Allen. 1990. Evapotranspiration and irrigation water requirements. ASCEManuals and Reports on Engineering Practice No. 70. American Society of Civil Engineers, New York, NY, USA.

Kaur, H. and S. P. Arora. 1984. Annual pattern of plasma progesterone in normal cycling buffaloes (Bubalus bubalis) fed two different levels of nutrition. Anim. Reprod. Sci. 7:323-332.

Madan, M. L. and B. S. Prakash. 2007. Reproductive endocrinology and biotechnology applications among buffaloes. Soc. Reprod. Fertil. Suppl. 64:261-281.

Mader, T. L., M. S. Davis, and T. Brown-Brandl. 2006. Environmental factors influencing heat stress in feedlot cattle. J. Anim. Sci. 84:712-719.

Marai, I. F. M., and A. A. M. Haeeb. 2010. Buffalo's biological functions as affected by heat stress - A review. Livest. Sci. 127:89-109.

Marai, I. F. M., A. A. El-Darawany, A. Fadiel, and M. A. M. Abdel-Hafez. 2008. Reproductive performance traits as affected by heat stress and its alleviation in sheep - A review. Trop. Subtrop. Agroecosyst. 8:209-234.

McGowan, M. R., D. G. Mayer, W. Tranter, M. Shaw, C. Smith, and T. M. Davison. 1996. Relationship between temperature humidity index and conception efficiency of dairy cattle in Queensland. Proc. Aust. Soc. Anim. Prod. 21:454.

Mellado, M., P. Romero, J. E. Garcia, F. G. Veliz, and J. R. Arevalo. 2010. The effects of ambient temperature and humidity on pregnancy rate in Beefmaster cows in a subtropical environment of Mexico. Livest. Sci. 131:149-154.

Morton, J. M., W. P. Tranter, D. G. Mayer, and N. N. Jonsson. 2007. Effects of environmental heat on conception rates in lactating dairy cows: Critical periods of exposure. J. Dairy Sci. 
90:2271-2278.

Oseni, S., I. Misztal, and S. Tsuruta. 2005. Genetic parameters for pregnancy rate in Holstein cattle under seasonal heat stress. Nigerian J. Genet. 19:43-57.

Palta, P., S. Mondal, B. S. Prakash, and M. L. Madan. 1997. Peripheral inhibin levels in relation to climatic variations and stage of estrous cycle in Buffalo (Bubalus bubalis). Theriogenology 47:989-995.

Parmar, A. P. and V. M. Mehta. 1994. Seasonal endocrine changes in steroid hormones of developing ovarian follicles in Surti buffaloes. Indian J. Anim. Sci. 64:111-113.

Patil, C. S., A. K. Chakravarty, A. Singh, V. Kumar, V. Jamuna, and V. Vohra. 2014. Development of a predictive model for daughter pregnancy rate and standardization of voluntary waiting period in Murrah buffalo. Trop. Anim. Health Prod. 46:279-284
Ravagnolo, O. and I. Misztal. 2002. Effect of heat stress on nonreturn rate in Holsteins: fixed-model analyses. J. Dairy Sci. 85:3101-3106.

Roenfeldt, S. 1998. You can't afford to ignore heat stress. Dairy Manage. 35:6-12.

SAS Institute 1996. Statistics, Version 9.2. SAS Institute. Inc. Cary, NC, USA.

Singh, R. and A. S. Nanda. 1993. Environmental variables governing seasonality in buffalo breeding. J. Anim. Sci. 71(Suppl.):119.

Thom, E. C. 1959. The discomfort index. Weatherwise 12:57-61.

Van Raden, P. M., A. H. Sandres, M. E. Tooker, R. H. Miller, H. D. Norman, M. T. Kuhn, and G. R. Wiggan. 2004. Development of a National genetic evaluation for cow fertility. J. Dairy Sci. 87:2285-2292.

Yousef, M. K. 1985. Stress physiology in livestock. CRC Press, Boca Raton, FL, USA. 